\title{
Customer Response towards Non-deceptive Counterfeit Brands
}

\author{
Md. Farhan Faruqui ${ }^{*}$, Md. Anamul Hoque ${ }^{\mathrm{a}}$, Fabliha Tasnim Hride ${ }^{\mathrm{b}}$ \\ a Assistant Professor, Department of Business Administration, East West University, Bangladesh. \\ b BBA Graduate, East West University, Bangladesh. \\ *Corresponding author's email address: farhan@ewubd.edu
}

\section{A R T I C LE IN F O}

Received: 01-12-2016

Accepted: 20-12-2016

Available online: 20-01-2017

\section{Keywords:}

Counterfeit brands;

Fashion conscious;

Perceived control behavior;

Price quality schema;

Price sensitivity;

Social marketing communication;

Status seeking;

Subjective norms.

\section{A B S T R A C T}

Universally counterfeiting is a very significant growing problem and profitable business, occurring both in less and well developed countries. A recent report, by OECD and the EU's Intellectual Property Office (2016), estimated the Imports of counterfeit goods to around $2.5 \%$ of global imports annually. However, this paper intends to measure the response of consumer towards non-deceptive counterfeit brand in Bangladeshi market. Both primary data by administering questionnaire and secondary data were collected. The research revealed that these consumers are price- sensitive but they also want to maintain status. Moreover, the consumers are also influenced by social media advertisements and past experience. The main contribution of the research is to demonstrate that consumers' intention to buy counterfeit products is dependent on the attitudes they have towards counterfeit brands.

JEL Classification:

D12; G22.

(C) 2017 The Authors. This is an open access article under the terms of the Creative Commons Attribution License 4.0, which allows use, distribution and reproduction in any medium, provided the original work is properly cited.

DOI: http://dx.doi.org/10.18533/rss.v2i1.122

ISSN 2378-8569(Print), ISSN 2378-8550(Online)

\subsection{Introduction}

Counterfeit brands are illegal, less-priced, and often low-quality copies of original brands that typically possess high brand value (Lai and Zaichkowsky, 1999). When consumers are aware that they are purchasing a counterfeit brand define as 'non-deceptive counterfeit' product. Since these consumers acknowledged about purchase of counterfeit are not legitimate, the manufacturers and retailers of original brands' cannot be blamed. (Ang et al., 2001). According to a new report by OECD and the EU's Intellectual Property Office (2016), the value of Imports of counterfeit goods are estimated to be around half a trillion dollars annually. This is equivalent to around $2.5 \%$ of global imports. This study also underlined that due to customer loyalty towards trademark and brand names, the counterfeit brand producers undermines the economy as well as endanger people's lives. Asia and South America have been suggested as the largest sources for counterfeit and pirated products (Ritson, 2007). China has been recognized as the world's most notorious country for supplying counterfeit goods (Business Insider, Jun. 25, 2013). This is prohibited to manufacture and distribute to supply counterfeit goods. As consumers' drive to buy counterfeit brand increases, it becomes critical to understand that how and why consumers are influenced and have favorable attitudes towards intention to purchase counterfeit brands even though there aware of product material. Specifically, the focus of this study is to achieve an in-depth understanding of consumers' orientations (social and personal) leading to attitudes towards the purchase 
intention to counterfeit brands here the study discuss about consumer response towards non-deceptive counterfeit brands (Demand side).

\section{$2.0 \quad$ Literature review}

\subsection{Consumer orientations}

Consumer orientations or characteristics have been the most basic concept in the literature of consumer behavior (McGuire, 1976; Pons, Mourali, \& Nyeck, 2006). Although the basic definition of orientation does not exist, Kassarjian (1971) referred that people only react or response on stimuli around them or any existing environmental situations. The study divide consumer orientation in two parts: Social and Personal.

\subsubsection{Social consumer orientation}

H1: Social consumer orientation (fashion consciousness, price-quality schema and status seeking) $\rightarrow$ Attitudes towards the intention to buy counterfeit brands and subjective norm.

Fashion consciousness: Schrank and Gilmore (1973) defined that socially derived appraisal and recognize products are fashionable and people fell greatest forces to get that product. As another explanation of fashion is a collective set of behavior that is socially approved for a specific time but is expected to change" (Summers, Belleau, \& Wozniak, 1992). Moreover, Fashion products is a vehicle of self-expression which typically performance as a tool to impress others. (Kaiser, 1990). Therefore, consumers' buying behaviors are motivated by their feeling towards fashion products that express themselves (Goldsmith et al., 1991).

H1a: Fashion conscious customers have positive attitudes toward intention to buy counterfeit brands.

Price quality schema: Price quality schema is an important factor in consumer behavior and a common belief among them. (Chapman and Wahlers, 1999). In this logic, consumers' tendency to believe that high price means high product quality and on the other hand low price reflects low product quality. That becomes more important when there is very few information about the product quality are available. (Tellis and Gaeth, 1990). However, the two main differences consumers' price perception between a counterfeit and an original brands are important factors related to attitude towards counterfeits (Huang et al., 2004). Previous studies have shown that price variance is a very significant variable when choosing a counterfeit product. (Cespedes et al., 1988; Cordell et al., 1996). brands.

H1b: Price-quality schema will reflect negative customers' attitudes toward intention to buy counterfeit

Status-seeking: Individual seek status to attain a position or rank in a society. Social status can be define as a form of self-presentation that express high or low prestige, regard, and esteem (Donnenwerth \& Foal, 1974, p. 786). Also, social status among consumers can be described by effect that relates to the concept of conspicuous consumption (Corneo \& Jeanne, 2005). In this perspective, bandwagon effect instead of the snob effect better explains consumers' perception of counterfeit brands, as snob effect reflects an increasing demand for those brands that are hardly consumed by others in the society (Leibenstein, 1950). However, Veblen's (1922) argue that consumers' desire to gain status by using conspicuous products that indicate consumers may not always use high prices product to achieve status but they may also purchase a large quantity of conspicuous product at low price product to gain self-esteem.

H1c: Status-seeking people have positive attitudes toward intention to buy counterfeit brands.

Whereas individuals belong to lower status are motivated to associate them with individuals who are in a higher class in the society and sometimes may feel reinforce to buy counterfeit brands due to the social influence (Eisend \& Guler, 2006). As pointed out by Mellott (1983), lower class people may be more willing to buy counterfeit brands for being a part of a relatively higher-class social group. Moreover, Islam et al. (2017) narrated that social influence implies the extent to which consumers believe that their friends and families should influence the use of a particular product.

H1d: Status-seeking people have strong subjective norm in the intention to buy counterfeit brands.

\subsubsection{Personal consumer orientation}

Perceived control behavior: Meng-Hsiang et al. (2006) define perceived control behavior as reflection of one's perceptions of the availability of resources or opportunities essential for performing a behavior. As such, 'perceived availability' can be seen as a part of perceived control behavior. The higher one's perceived availability, the higher one's perceived simplicity of acquisition and the higher one's perceived behavioral control. Ajzen (1991) also recommends perceived control behavior is highly accurate in predicting 'intentions to perform behaviors of different kinds'. In addition, Mannetti et al. (2002) found that perceived control behavior is positively associate to the prediction of purchase intentions.

H2: Personal Consumer Orientation (ethical value, social responsibility, risk awareness and integrity) $\rightarrow$ Subjective Norm and Perceived Control over the intention to buy Counterfeit Brands.

Ethical value: Ethical value have been considered as the assessment of operating a business in terms of earning profits for social welfare (Wilson, 1975). Recent studies have emphasized the purchase of pirated 
products are growing problem of consumers' involvement in activities (McMohan \& Harvey, 2007; Pelsmacker, Driesen, \& Rayp, 2005; Rawwas, Swaidan, \& Oyman, 2005; Wan et al., 2009). An increasing number of researchers have focused on consumers' ethical value that motivates them to behave in a specific manner in order to better understand why consumers involve themselves in such kind of activities. (e.g., Albers-Miller, 1999; Ang et al., 2001; Muncy\& Vitell, 1992).

brands

H2a: Stronger ethical customers have greater perceived control towards the intention to buy counterfeit

Sincerity towards social responsibility: As concerns for the society and environment increased people become more social conscious. Marketers segmented product that promote social and environmental well-being.

Environment Conscious: The concern for environmental well-being was around 1970s when people realized that the environment was vulnerable to damages and had limited resources. According to refer to Lewis et al. (2009), the OECD report (2008), the BASCAP reports (2009), Gessler (2009) and Pollinger (2008) the most frequently mentioned significances of counterfeit has on society is environment Consciousness. In the academic literature that social responsibility has been dominated by issues that have environmental dimensions, leading to an incomplete coverage of the social dimension (Webb, Mohr, \& Harris, 2008).

Job losses: A study of Counterfeiting and Consumer Behavior; Dennis De Cat, onderleiding van, Prof. Dr. I. Vermeir, 2010 find that counterfeiting is responsible for job losses at a large scale in original brands' companies and their subsidiaries. Counterfeit goods affect original brands' in different ways. The lower demand for original goods and services result for decreases business revenues and creates a competitive advantage for those enterprises those are free-rider.

H2b: Stronger socially responsible customers have greater perceived control towards the intention to buy counterfeit brands.

Risk averseness: Risk averseness is defined as the tendency to avoid risks and is generally considered a personality traits. (Bonoma and Johnston, 1979; Zinkhan and Karande, 1990). The risk is vary, the risk might include different components, such as performance, financial, safety, social, psychological, and time dimensions (Havlena and DeSarbo, 1991).

Perceived Risk arise when consumers judge what the possibilities of positive and negative occurrences. This judgment will influence every stage of the buyer decision-making process. (Havlena and DeSarbo, 1991)

Performance risk refers that the fear that a product will fail to deliver promised functions or benefits. (Havlena and DeSarbo, 1991).

Physical risk contains counterfeit product long lasting and durability risk (Joshie Juggessur and Geraldine Cohen, 2009).

Financial risk involves the potential loss of money when buying a counterfeit product (Havlena and DeSarbo, 1991).

H2c: High Risk awareness customers have greater perceived control towards the intention to buy counterfeit brands.

Integrity: Indeed, research shows that consumers' willingness to buying counterfeit products is negatively related to attitudes towards lawfulness (Cordell et al., 1996). Though purchasing counterfeit is not a crime, consumer participation in a counterfeit transaction supports illegal acts. Consumer's respect for lawfulness reflect that how much they are engage in counterfeiting. brands.

H2d: Consumers of integrity have greater perceived control towards the intention to buy counterfeit

H3: Subjective Norm and Perceived Control of Behavior and Attitudes $\rightarrow$ Intentions to Purchase Counterfeit and Original Brands.

Subjective norm: Subjective norm is a social factor that perceived social influence to perform or not to perform an approved behavior (Ajzen, 1991). As Fishbein and Ajzen (1975) explained that consumers are liable to social influence and seek approval from people who are important to them. On this subject of counterfeits, family friends, peers and relatives may act as contributors to the consumption, depending on how much this behavior is accepted to them. Consumers are motivated, when expertise from others influences their choice (e.g. when one does not know the product category), and also, when they are more interested in making a good impression to others (Bearden et al., 1989). Subjective norm indicates an individual's perceived social reinforcement to buy counterfeit fashion brands.

H3a: Greater perceived control of customers towards intention to buy counterfeit brand have negative subjective norms towards intention to buy counterfeit brand

H3b: Greater perceived control of customers towards intention to buy counterfeit brand have less intention to buy the counterfeit brands.

Attitudes: Tom et al. (1998) indicated that consumers who are influence by counterfeit brands and tend to purchase counterfeit in the future as compared to others who do not influence by counterfeit brands and purchase original brands. Kim and Karpova, (2009) found that attitudes towards purchasing counterfeits was found to be positively associated with the intentions to purchase counterfeits. Comparable results of a positive relationship between attitudes and intentions to purchase were found in the context of pirated music (Chang, 
1998; d'Astous et al., 2005; Kwong \& Lee, 2002), software piracy (Peace, Galletta, \& Thong, 2003), and shoplifting (Tonglet, 2001).

Ajzen (1991) defines 'subjective norm' as "the perceived social reinforcement to perform or not to perform the approved behavior". Thus, subjective norm contributions to measure social influences. Social influences refer to the potential effect have positive attitudes to buy counterfeits.

H3c: Consumers' stronger subjective norm towards intention to buy counterfeit brands have positive attitudes towards the intention to buy counterfeit brands.

H3d: Consumers' positive attitudes towards counterfeit brands have a higher intention to buy the counterfeit brands. brands.

H3e: Consumers' positive attitudes towards counterfeit brands have less intention to buy the original

Product attributes: Counterfeits are low quality duplicates of the real product and there is a rising trend towards high quality counterfeits (Hilton et al., 2004; OECD, 2008). Over the years, counterfeit businesses have enjoyed increased quality levels due to the extensively available, cheap and easy accessible new production technologies. (Gessler,2009; Alcock, 2003). Gentry et al. (2006) even state that the ability to differentiate counterfeit goods from genuine items becomes less important as the quality of many counterfeits is now more alike the quality of the real product. In fact in a study, consumers claim that there might not be any noticeable difference in perceived quality with real product. (Tom et al., 1998). brands.

H4: Counterfeit product attributes have positive impact of attitudes on the intention to buy counterfeit

Past purchase of counterfeit: Research has shown that counterfeits consumers are different from nonconsumers. Counterfeit consumers have past purchase experiences that make them less risky and build trust the seller of counterfeit. (Ang et al., 2001). Smith et al. (2008) found self-reported past experience of customer was a strong predictor of self-reported purchase intentions. Therefore, the role of past purchase behavior and its effect on future purchase behavior in a non-counterfeit. Also Ouellette and Wood (1998) suggest past behavior has a significant influence on purchase intentions and therefore on actual behavior. And also the number of occurrence for performing a certain behavior has a direct impact on future behavior. (Ouellette and Wood, 1998) brands.

H5: Past Purchase of Counterfeit products have impact of attitudes on the intention to buy counterfeit

Social marketing communication: A study of Lenhart et al., (2010) find the $57 \%$ of social networking site users are very young between 18 to 29 years old and have a personal profile on several social media websites. Chaudry and Stumpf (2007) include social media communication on their conceptual model for more extensive understanding factors that persuading consumer complicity. As counterfeit brands are unlawful, marketer cannot promote directly by using any legal system. Therefore, counterfeits' marketers can easily reach to their consumer by social media with any legal registration. brands.

H6: Social marketing communications have positive impact of attitudes on the intention to buy counterfeit

Price sensitivity: Price sensitivity is the most frequently mentioned variable affecting purchase intention of counterfeit goods (Penz et al., 2009; Large, 2009; Albers-Miller, 1999; Chaudry, 2008; Tom et al., 1998; Ang et al., 2001; Bloch et al., 1993; Large, 2009). The price of a counterfeit item is mostly set as a fraction of the price of the matching real brands. (Penz and Stöttinger, 2005; Ang et al., 2001; Tom et al., 1998). Several sites will be presented, offering cheap fake products. It is this low-pricing strategy that attracts consumer's attention on purchasing a counterfeit. People want to purchase original brands but due to poor economic condition they cannot afford that. Thus; those customer who cannot afford original brands, they purchase the counterfeit brands to satisfy their desire (Chuchinprakarnm, 2003; Chaudhry et al., 2009).

H7: Price Sensitivity as a moderator in the relationship between Attitudes and Intentions to Purchase Counterfeit and Original Brands.

H7a: Higher price sensitivity will strengthen the impact of attitudes on the intention to buy counterfeit brands.

H7b: Higher price sensitivity will weaken the impact of attitudes on the intention to buy original brands.

\subsection{Research gap}

Counterfeiting has become the most profitable businesses in Asia; this phenomenon is very alarming for a country's economy. It is a threat for original brands, job losses for general people and also creates an impact on personal ethics. Many study's have been conducted to identify the reasons to buy counterfeits goods. However, so far no study analyzed the variance inflation of the factors. Therefore, this study is conducted to understand variance inflation among the factors that influence consumers to buy counterfeit goods. This study will help original brands' manufacturers, distributors, and suppliers to protect their brands even the government also to save country's economy growth. 


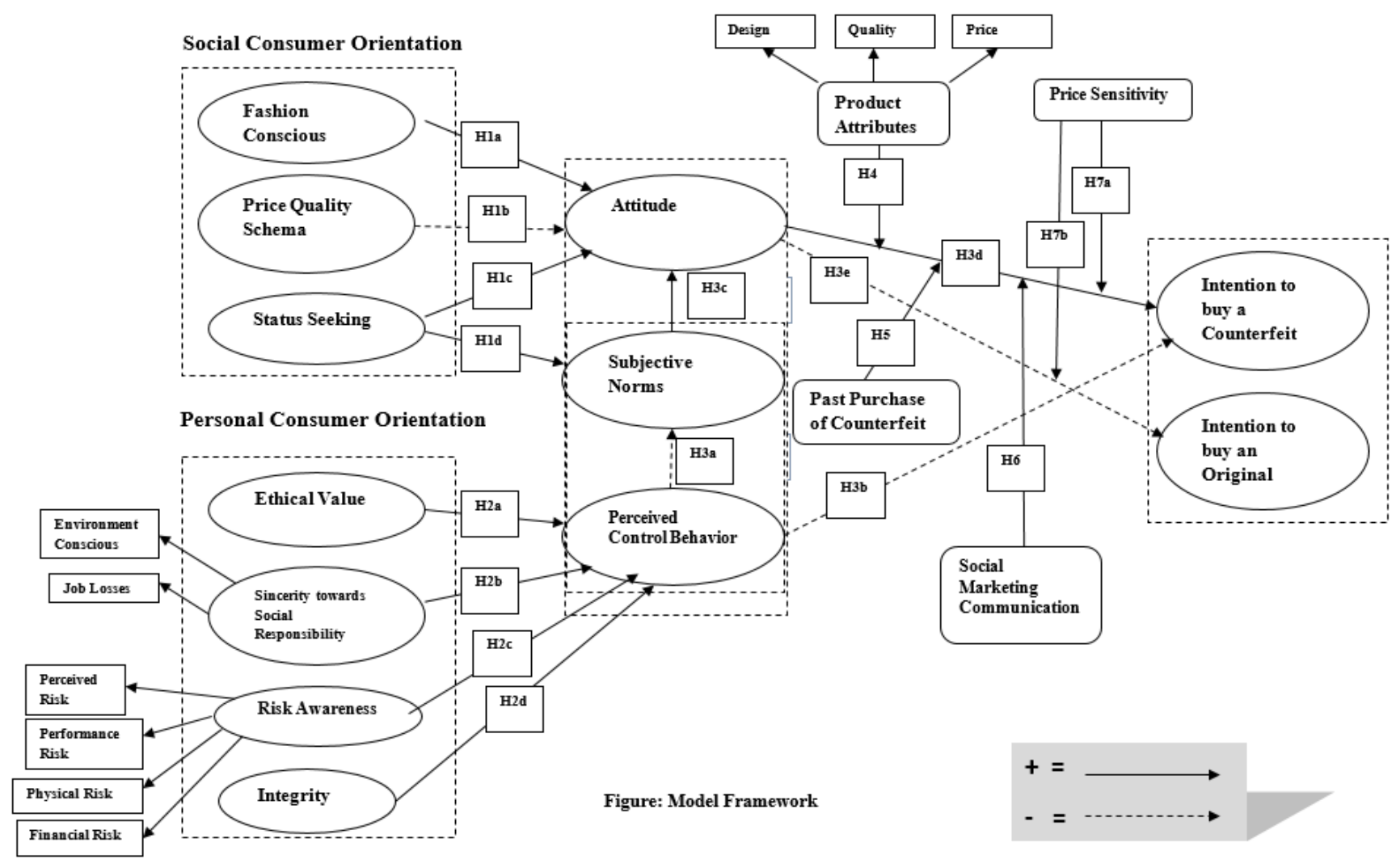

\subsection{Research design}

All the relevant data of the study were collected from both primary and secondary sources. The secondary data were collected by analyzing different journal article, books and websites. While, the Primary data were collected by developing a structure questionnaire. All the items of the questionnaire are adopted form the existing literature. The questionnaire had three parts. The first group of questions was prepared to determine demographic profile of respondents. The second group of questions was prepared to determine the psychographic profile and the Behavior of the respondents regarding counterfeit brands (Brand preference, frequency of purchasing of counterfeits, how often they purchase counterfeit products etc.). The third group of questions included variables prepared to determine the Consumer Response towards Counterfeit Brands, influencing factors to buy counterfeits and buying behaviors consumers to on a 5-point Liker scale. The respondents were asked to rate their opinions on the scale between "Strongly agree" and "Strongly Disagree". A total of 56 questions were included in the final questionnaire. The survey was conducted among the 200 respondent among different profession according to cluster sample size. All the literate people above 16 years old are taken as the population of this study. As a technique non-probability, convenience sampling was applied as it easy to send a link of online questionnaire to individuals on mobile phone's contact list, to individuals who are connected in social networking websites for instance Facebook, LinkedIn, and Google+ as well as to individuals who are known in person. Finally, the gathered data from the survey were analyzed using statistical techniques. The general information were analyzed using simple tabular presentation. Rest of the questions were analyzed using regression and variance inflation factors analysis procedure.

\subsection{Analysis}

\subsection{Sample profile}

To analyze variable with statistical tools nine independent variables - The responses included 57.5 percent male and 42.5 percent female. 15 percent, 40 percent of the respondents were respectively at the average age group of below 20 years and 21 to 30 years, 25 percent of the respondents were at the age group of 31-40 and 5 percent is above 51 years. Educational qualification of 25 percent respondents is S.S.C. 25 percent H.S.C. 25 percent Undergraduate, 23.5 percent Graduate and 1.5 percent others. 39.5 percent of respondent were students, 31 percent private employee and 13 percent respondent were government employee 13.5 percent were businessman and 3 percent were others. Most of the respondent, 35 percent and 27 percent, were belong to the group of average monthly income 20,001-50,000 TK and below 20,000T K correspondingly. 


\subsection{Regression analysis}

Regression Equation, $Y=\alpha+\beta \chi$

$\mathrm{Y}=$ Dependent variable (Intention to buy counterfeit)

$\alpha=$ Intercept

$\beta=$ Coefficient of independent variable

$\chi=$ Independent variable (factors to influence to buy counterfeit)

The value of R Square (0.849) and Adjusted R-square (.842) predicting a strong relationship between the set of regressor and the regress and (table 2). That means the purchase intention of counterfeit brands is only $84.2 \%$ influenced by fashion conscious, price quantity schema, status seeking, perceived control behavior, subjective norms, and product attributes, past purchase of counterfeit, social marketing communication, price sensitivity. The remaining $15.8 \%$ are influenced by some other factors that the study have not considered. These factors may include such as cultural value, Social conformity, living conditions, lack of knowledge of counterfeits. These factors may be consider for the further research.

\subsection{Testing hypothesis}

H1: Social Consumer Orientation (fashion consciousness, status seeking and price-quality schema) $\rightarrow$ Attitudes toward the Purchase of Counterfeit Brands and Subjective Norm.

H1a: From table 4, it has been shown that there is an insignificant positive relationship between fashion consciousness and attitudes toward non-deceptive counterfeit brands when all variables are adjusted. However, the unadjusted variable shows very significant positive relationship. This means that fashion consciousness contributes more than $84.2 \%$ attitudes towards non-deceptive counterfeit brands. The result of the study $(F=266.521)$ support H1a (table 5). Dennis De Cat, onderleiding van, Prof. Dr. I. Vermeir (2009-2010) and also Wee et al. (1995) reveal that fashionable counterfeit brands attract consumer by the equivalent exterior, quality and image projected by the counterfeit version compared to the originals brands. The results also indicate that the influence of fashion conscious has more positive attitudes toward the intention to buy counterfeit brands.

H1b: From table 4, it has been shown that there is an insignificant negative relationship between Quantity Schema and attitudes toward non-deceptive counterfeit brands when all variables are adjusted. However, the unadjusted variable shows very significant positive relationship. This means that Quantity Schema contributes less than $33 \%$ attitudes towards non-deceptive counterfeit brands. The study ( $\mathrm{F}=366.684)$ shows that $\mathrm{H} 1 \mathrm{~b}$ is accepted (table 5). The results show that those people have higher level of price-quality schema they are not willing to buy counterfeit brands. Price quality schema is very significant predictor for attitude toward counterfeit brands (Phau et al., 2008). Dennis De Cat, onderleiding van, Prof. Dr. I. Vermeir (2009-2010) and Lichtenstein and Burton (1989) also found that consumer has to consider the price quality schema relationship in a productspecific approach.

H1c: From table 4, it has been shown that there is an insignificant positive relationship between Quantity Schema and attitudes toward non-deceptive counterfeit brands when all variables are adjusted. Even, the unadjusted variable shows very significant positive relationship. This means that fashion consciousness contributes more than $88.8 \%$ attitudes towards non-deceptive counterfeit brands. The study ( $F=736.909)$ shows that H1c is accepted (table 5). The results show that people who have strong stronger status-seeking tendency, they are highly motivated to buy counterfeit brands. Original brands are simply use to obtain status and prestige in the society. (Wee et al., 1995). Moreover, fashion brands specify a socioeconomic status in a society so consumers who seek status and high self-esteem they have favorable attitudes toward fashion brands as it reflects a high status in a society. (Damhorst, Miller, \& Michelman, 2001).

H1d: The result ( $F=860.697$ ) support H1d (table 5). Simultaneously, Wilcox et al. (2009) found that consumers seek for status and prestige to be a part of the higher social class and they feel pressure to purchase the counterfeit version of original brands.

H2: Personal Consumer Orientation (ethical value, social responsibility, and integrity) $\rightarrow$ Subjective Norm and Perceived Control over the Purchase of Counterfeit Brands.

The P value is significant (table $3,4,5$ ) both adjusted and unadjusted model in case of perceived control behavior. When all situation in considered perceived control behavior decrease $20.5 \%$ attitudes towards nondeceptive counterfeit brands by Ethical Value (28.3\%), Social Responsibility (30.8\%), Integrity (14.8\%) and Risk Awareness (48.1\%). That can be state that Perceived control is more depended on risk awareness (48.1\%) if consumers have more risk awareness so they do not buy counterfeit.

H2a: The study $(\mathrm{F}=190.019)$ shows that $\mathrm{H} 2 \mathrm{a}$ is accepted (table 5). To support the finding (Cherrier, 2009), (Kwong et al., 2009), (Muncy and Vitell, 1992), (Shaw et al., 2005), and (Wan et al., 2009) pointed out that consumers' ethical value and social responsibility inspire their perception and behavior to become more social concern. Ethical people are more sensitive and responsible to their society.

H2b: The study $(\mathrm{F}=34.214)$ also support $\mathrm{H} 2 \mathrm{~b}$ (table 5). The results show that stronger social responsibility has greater perceived control over the intention to purchase of counterfeit brands. Subjective norms impose people to purchase counterfeit brands. As ethical value and social responsibility have negative 
relation with subjective norm, it should be consider that when consumers have high ethical value and social responsibility, they are not affected by uniform set of subjective norms. They are strictly influenced by their idiosyncratic personal dispositions to make decisions. (Dennis De Cat, onderleiding van, Prof. Dr. I. Vermeir, 20092010)

H2c: The finding ( $F=677.530)$ shows that $\mathrm{H} 2 \mathrm{~d}$ is accepted (table 5). In the context of counterfeits, Huang et al. (2004) found a significant association between risk awareness and perceived control over the attitude towards counterfeit brands. The test results show that stronger risk awareness has greater perceived control over the intention to buy counterfeit brands.

H2d: Consumers establish an illegal or an immoral action by purchasing counterfeit brands (de Matos et al., 2007). If consumers consider integrity as vital component, there is less probability to have positive attitudes to buy counterfeit brands. (Ang et al., 2001). Therefore, Integrity reflects consumers' preference toward lawfulness and reluctance for counterfeit brands and the study ( $\mathrm{F}=283.581)$ shows that H2c is accepted (table 5). The results show that stronger integrity has greater perceived control over the intention to purchase counterfeit brands. Habitually individuals are seeking equilibrium with his activities to maintain positive self-esteem, they have a high level of integrity. (Ferguson, 2009). Brands.

H3: Attitudes, Subjective Norm, and Perceived Control $\rightarrow$ Intentions to Purchase Counterfeit and Original

H3a: The study $(\mathrm{F}=121.481)$ shows that H3a is accepted (table 5). Consumers with auspicious attitudes toward intention to buy counterfeit brands may not realize that obtaining these brands can be a social concern (Kim and Lee, 2004). Reference group can be defined as a group of people whose attitudes and standards influence an individual's current behavior (Schiffman and Kanuk 2007). Therefore, the greater perceived control over the purchase of a counterfeit brand; have the more negative subjective norms toward the purchase of counterfeit brands and vice versa. The person who have less perceived control, they are very influenced by reference group.

H3b: The study $(\mathrm{F}=55.729)$ shows that $\mathrm{H3b}$ is accepted (table 5). This result reflects Madden, Ellen, and Ajzen's (1992) conceptualization of PCB; that is, the individuals with a higher level of perceived control have a stronger willpower and determination in deciding whether (or not) to perform the final behavior. Therefore, the greater perceived control over the purchase of counterfeit brands has a lower intention to buy the counterfeit brands. According to the effects of consumer Orientations on the consumption of counterfeit luxury brands; Vertica Bhardwaj (2010) the relationship between perceived control and intentions to purchase counterfeit brands was negative and significant.

H3c: The study (141.789) shows that H3a is accepted (table 5). The results show that the stronger subjective norms in the purchase of counterfeit brands have more constructive attitudes toward the purchase of counterfeit brands. That means people who are more influenced by subjective norms, they have more constructive attitudes to purchase of counterfeit brands. Vertica Bhardwaj (2010) also found the significant and positive result between subjective norm and attitudes to purchase counterfeit brands.

H3d\&e: The study (143.389) shows that H3d and H3e both are accepted (table 5). Buyer's favorable attitude for counterfeit goods can extremely define their purchase intention (Yoo and Lee, 2009). Some consumer belief counterfeit is a smart choice which others are feel this practice is illegal (De Matos et al., 2007). The results show that the more constructive attitudes toward the purchase of counterfeit brands; have a higher intention to buy the counterfeit brands and lower intention to buy the original brands.

H4: The study ( $F=322.145)$ shows that H4 is accepted (table 5). A rising trend of high quality counterfeits are growing in the market thought counterfeits are low quality copies of the real product (Hilton et al., 2004; OECD, 2008). The results show that product attributes have more positive influence of attitudes on the intention to purchase counterfeit brands. This means that product attributes contributes more than $18.9 \%$ attitudes towards non-deceptive counterfeit brands and also in unadjusted model it increased by $88.7 \%$.

H5: The study ( $\mathrm{F}=307.839)$ shows that H5 is accepted (table 5). The results show that Past Purchase of counterfeit has more positive effect of attitudes on the intention to purchase counterfeit brands. Past experience of counterfeit goods emerge a significant positive relationship to purchasing counterfeit further. (Dennis De Cat, Onderleiding van, Prof. Dr. I. Vermeir, 2010). Counterfeit consumers are completely different from non-consumers of counterfeit products meanwhile the past consumer of counterfeit have belief that using counterfeit is not an unethical act and the counterfeit product is less risky and trustworthy from their post purchase counterfeit behavior (Ang et al., 2001). From table 3 past purchase of counterfeit contributes more than $86.4 \%$ attitudes towards non-deceptive counterfeit brands in unadjusted model however when all factors are considered past purchase is not significant.

H6: The study $(\mathrm{F}=392.189)$ shows that H6 is accepted (table 5). The results show that Social marketing communication more positive impact of attitudes on the intention to purchase counterfeit brands. According to Boyd \& Ellison (2008) social networking sites provide a platform to analyze the psychological impact of online interaction of customer. Moreover, counterfeit goods no legal option to promote their brands rather than social media. The social media communication of counterfeit contributes more than $28.3 \%$ attitudes towards nondeceptive counterfeit brands and also significant in unadjusted model (table 4). And also the highest percentage (30\%) of media preference get internet and highest respondent's' age group is 21-30 years people. Also related 
the study of Lenhart et al., (2010) which find the 57\% of social networking site users are very young between 18 to 29 years old. That can be conclude that consumers' of counterfeit brands are young people whose are most engage in social media which motivate them to get counterfeit brands.

H7a\&b: The price sensitivity is significant in both adjusted and unadjusted model and its' contributes more than $49 \%$ attitudes towards non-deceptive counterfeit brands (table 4$)$. The study $(\mathrm{F}=407.800)$ shows that $\mathrm{H} 7 \mathrm{a}$ and $\mathrm{h} 7 \mathrm{~b}$ both are accepted (table 5). The results show that higher level of price sensitivity will create more strengthen influence of attitudes of purchase counterfeit brands beside that it also weaken the influence of attitudes to purchase original fashion brands. Thus, those customers who cannot buy original brands because of high price, buy low priced counterfeit products or services to satisfy their needs and wants (Chuchinprakarnm, 2003; Chaudhry et al., 2009). Price sensitivity is the most significant variable which is the highest contributor on attitudes towards non-deceptive counterfeit brands and also from sample profile the highest respondent came from lower middle class income; that can be state that the consumer of counterfeit brands usually motivated to counterfeit goods for their lower economic condition.

\subsection{Variance inflation factors analysis}

Some aspect indicate that multicollinearity arises in this model (table 4). The test shows Fashion conscious, Product Quantity Schema, Status Seeking, Social Marketing Communication and Price Sensitivity have high variance inflation factors. Kassarjian (1971) referred to Social Consumer Orientation that people only interact by stimuli around them or any existing environmental situations. Fashion conscious, Product Quantity Schema, Status Seeking are elements of Social Consumer Orientation. And Social media communication also have strong relationship with Social Consumer Orientation. Social Oriented people are also influenced by reference price and Price Sensitivity arise. According to Donald R. Lichtenstein, Nancy M. Ridgway, Richard G. Netemeyer (2008), "Price Perceptions and Consumer Shopping Behavior" Prestige sensitivity as favorable perceptions of the price cue based on feelings of prominence and status that higher prices signal to other people about the purchaser. Therefore (table 6) high status seeking people have high price quality schema and also correlate $97 \%$.

At the same time status seeking could have price sensitivity. Consumers compare products and price sensitivity arise when consumer are more social whose influenced by reference price. Consumers might compare the benefits of a product from different perspectives like as functional, social, emotional, and conditional situation (Sheth, Newman and Gross, 1991; Sweeney and Soutar, 2001). Status seeking and price sensitivity are $98.2 \%$ strongly positively correlated with each other (table 6). That means the consumers of counterfeits are price sensitive and also they also seeking status. And also, status seeker people are very social. Haung and Leung (2009) had explored that self-esteem and life satisfaction are destructive effect of a person's well-being in relation by using of social media. It is can be states that Status Seeking people are get more influenced by social media. Status seeking and social marketing communications are $97.2 \%$ (table 6) strongly positively correlated with each other. That means the consumers of counterfeits seeking status also influenced by social media ads.

That can be concluded, usually Status seeking people have price quantity schema. At the same time if status seekers are price sensitive so they influence by social media marketing and buy the counterfeit product.

\subsection{Discussion, limitation and future research}

Counterfeit consumers are mostly buying counterfeit because of price sensitivity. People are buying counterfeit because of low economic conditions. They buy counterfeits to maintain status. Thought some consumers have good economic condition, they are more prices sensitive. And they are less personal oriented which mostly dependent on risk awareness. Counterfeit brands have same product attributes which attracts them. The consumers are more socially oriented and affected by subjective norms. Social media ads influence them to buy counterfeits and past experience of counterfeits are having a vital role here. This study has taken only 200 convenience sample size. The result could be more precise and reliable if a larger sample had been taken, but there was the constraint of time and resources. The research is conduct at urban area (Dhaka city), results could be varied if the survey also take sample from rural areas consumers. And the study is that the overall attitude construct was measured on nine variable. Further research variable should be considered as cultures (Lazar, 969), Values and religion (Allport and Ross, 1967), social conformity (Grubb \& Hupp, 1968), Place/ Situational factors (Albers-Miller, 1999), Psychographic factors (Fernandes, 2013 \& Anget al. 2001) and so on.

\subsection{Recommendation and consultation}

Counterfeiting of original brands has become a severe global problem which cannot come up with a solution instantly. (Phau et al., 2009). Therefore, it requires long-term strategic planning, legal policy making, and its implementation that target that consumer who have intention to buy counterfeit brands.

- It requires to enforce strong law to protect intellectual properties. The law enforcement has to apply to supply side (manufacturers, distributors, sellers) and demand side (consumer) as well. As Social Marketing Communication play very significant role, Bangladesh ICT Division can impose stick law over internet to promote product. 
- Government need to plan strategic ways to discourage consumers to buy counterfeit products and spread the awareness about the drawbacks of counterfeit goods to the society as well as the economy. Government might be organized advocate literacy training/camps. As past purchase experiences have a great impact, once a customer use a counterfeit product then it would become habit.

- $\quad$ As Price Sensitivity show more significant result, Originals brands should extend brand line with some reasonable-price products. Specifically targets young consumers may help in achieving a long-term success in reducing demands of counterfeit brands.

- To maintain price-quality schema perception toward original brands, managers may design designing persuasive messages to improve consumers' perception of quality in original brands.

Government, Policy makers, anti-counterfeit organization and marketers should implements the strategies to reduce counterfeits.

\section{References}

Al-Rafee, S., \& Cronan, T. P. (2006). Digital piracy: Factors that influence attitude toward behavior. Journal of Business Ethics, 63(3), 237-259.

Ajzen, I. (2005). Attitudes, personality, and behavior. McGraw-Hill Education (UK).

Augusto de Matos, C., Trindade Ituassu, C., \& Vargas Rossi, C. A. (2007). Consumer attitudes toward counterfeits: a review and extension. Journal of consumer Marketing, 24(1), 36-47.

Triandewi, E., \& Tjiptono, F. (2013). Consumer intention to buy original brands versus counterfeits. International Journal of Marketing Studies, 5(2), 23.

Febrina. (2006, September 20). Consumers, rich and poor, pick fake goods. Retrieved from Thejakartapost: http://www.thejakartapost.com/news/2006/09/20consumers-rich-and-poor-pick-fake-goods.html

Gentry, J. W., Putrevu, S., \& Shultz, C. J. (2006). The effects of counterfeiting on consumer search. Journal of Consumer Behaviour, 5(3), 245-256.

Islam, M. S., Karia, N., Soliman, M. S. M., Fouji, M. H., Khalid, J., \& Khaleel, M. (2017). Adoption of Mobile Banking in Bangladesh: A Conceptual Framework. Review of Social Sciences, 2(8), pp.01-08.

Phau, I., Teah, M., \& Lee, A. (2009). Targeting buyers of counterfeits of luxury brands: A study on attitudes of Singaporean consumers. Journal of Targeting, Measurement and Analysis for Marketing, 17(1), 3-15. Irena Vida; Determinants of Consumer Willingness to Purchase Non-Deceptive Counterfeit Products.

OECD and the EU's Intellectual Property Office Report, Trade in Counterfeit and Pirated Goods - Mapping the Economic Impact (2016), (www.oecd.org/industry/global-trade-in-fake-goods-worth-nearly-half-atrillion-dollars-a-year.htm)

Mourad, S., \& Valette-Florence, P. (2011). The effects of counterfeit on luxury brand buying behavior, in terms of consumption experience.

Bhardwaj, V. (2010). The effects of consumer orientations on the consumption of counterfeit luxury brands.

\section{Appendix}

Table 1: Reliability statistics

Cronbach's Alpha

No of Items

0.972

Table 2: Model summary (Regression)

\begin{tabular}{lrrrr}
\hline Model & $\mathrm{R}$ & R Square & Adjusted R-square & Std. Error of the Estimate \\
\hline 1 & $.922^{\mathrm{a}}$ & .849 & .842 & .04954 \\
\hline
\end{tabular}

Table 3: Coefficients

\begin{tabular}{lrr}
\hline Independent Variables & Standardized Coefficient- $\beta(\mathrm{P})$ & VIF \\
\hline Ethical Value & $.148(.000)$ & 3.912 \\
Social Responsibility & $.283(.000)$ & 1.136 \\
Risk Awareness & $.481(.000)$ & 5.832 \\
Integrity & $.308(.000)$ & 2.648 \\
\hline
\end{tabular}

Table 4: Coefficients and VIF 


\begin{tabular}{lrrrr}
\hline Independent Variables & $\begin{array}{r}\text { Standardized } \\
\text { Coefficient }(\beta)- \\
\text { Adjusted (P) }\end{array}$ & $\begin{array}{r}\text { Standardized } \\
\text { Coefficient }(\beta)- \\
\text { Unadjusted }(\mathrm{P})\end{array}$ & VIF & $\begin{array}{r}\text { Cronbach's Alpha } \\
(\mathrm{N})\end{array}$ \\
\hline Fashion Conscious & $.045(.665)$ & $.842(.000)$ & 13.773 & .886 \\
Price Quality Schema & $-.033(.777)$ & $.859(.000)$ & 16.708 & .940 \\
Status Seeking & $.092(.735)$ & $.888(.000)$ & 92.602 & .972 \\
Perceived Control & $-.205(.018)$ & $.779(.000)$ & 9.324 & .828 \\
Subjective Norms & $-.097(.177)$ & $.767(.000)$ & 6.435 & .795 \\
Product attributes & $.189(.031)$ & $.887(.000)$ & 9.559 & .837 \\
Past Purchase & $.150(.059)$ & $.864(.000)$ & 7.889 & .836 \\
Social Marketing Communication & $.283(.049)$ & $.902(.000)$ & 25.806 & .937 \\
Price Sensitivity & $.490(.012)$ & $.897(.000)$ & 47.182 & .855 \\
\hline
\end{tabular}

Table 5: ANOVA

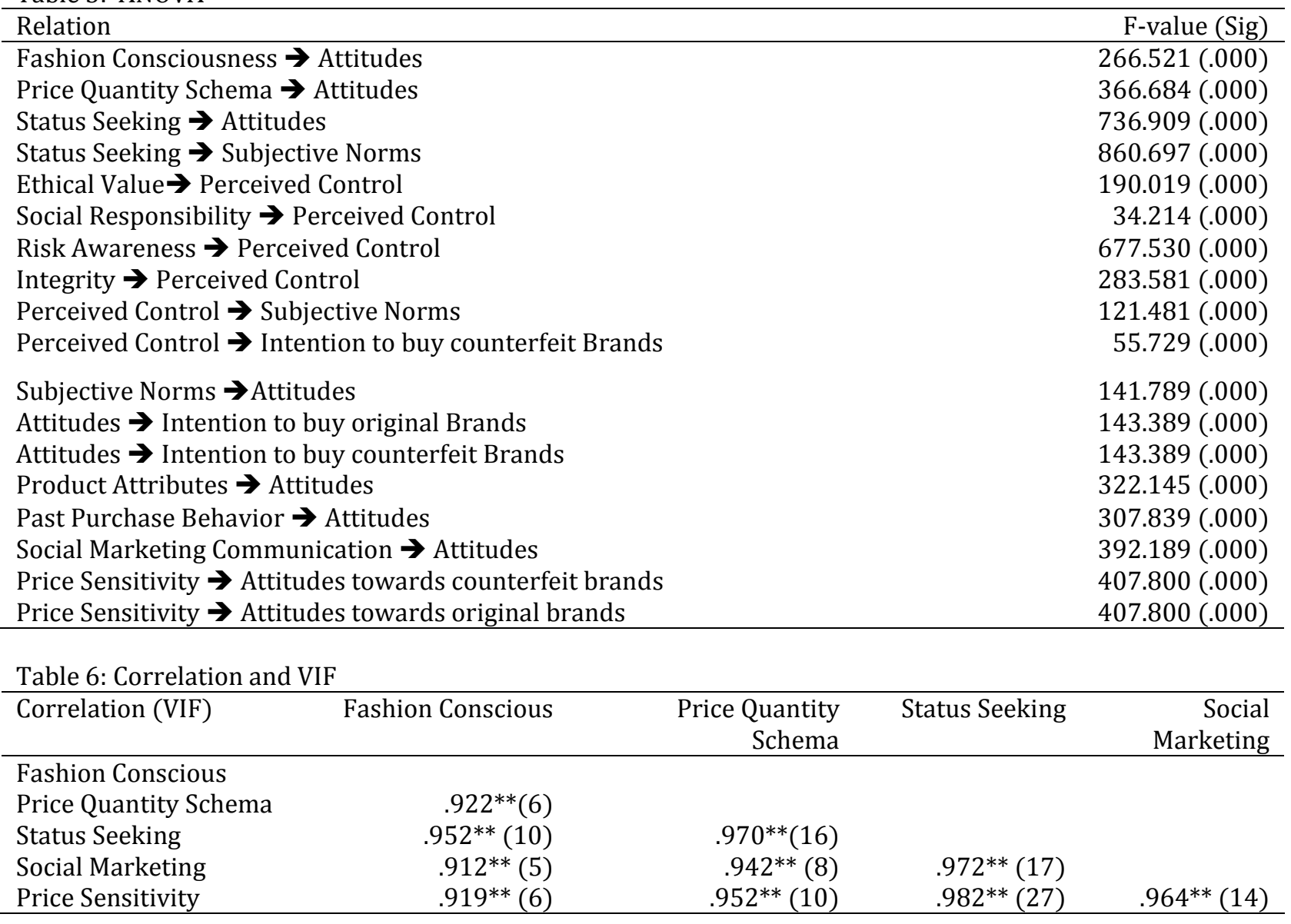

